\title{
Memorias incómodas: la División Azul en la literatura española contemporánea
}

\section{Uncomfortable Memories: the Blue Division in Spanish Contemporary Literature}

\author{
Valeria Possi \\ Investigadora independiente \\ vlr.possi@gmail.com \\ ORCID iD: https://orcid.org/0000-0003-1507-2392
}

\section{RESUMEN}

El artículo se centra en un grupo de novelas históricas contemporáneas que relatan las vivencias de unos personajes que durante la Segunda Guerra Mundial se alistaron en la División Azul para luchar contra el comunismo en la Unión Soviética, al lado del ejército de la Alemania nazi. En el texto se indagan las maneras de representar a estos personajes de ideología derechista y falangista en el contexto actual de la recuperación de la memoria histórica acerca de episodios relacionados con la Guerra Civil española y la dictadura franquista. La novelización de los personajes divisionarios en las obras de Almudena Grandes, Juan Manuel de Prada, Pío Moa, Ignacio del Valle y Lorenzo Silva adopta en algunos casos un andamiaje maniqueo, mientras que en otros refleja una postura más crítica y plural, abierta a la reflexión metanarrativa acerca de la escritura de unas memorias conflictivas e incómodas en el presente contexto literario y cultural español.

Palabras Clave: novela histórica contemporánea; División Azul; Segunda Guerra Mundial; memoria histórica.

\begin{abstract}
This article analyses a series of contemporary historical novels that focusses the narration on the characters' experiences when fighting -as soldiers of the Spanish División Azul and alongside the German's army- communism in the Soviet Union. Furthermore, it concentrates specifically on the different ways the characters' right wing and fascist ideology are portrayed taking into account the current theoretical approach on Historical Memory that revisits events that took place during the Spanish Civil War and Franco's dictatorship. The fictionalization of those characters that joined the Spanish División Azul in the novels written by Almudena Grandes, Juan Manuel de Prada, Pío Moa, Ignacio del Valle y Lorenzo Silva shows that in some authors there is a clear Manichaean narrative strategy while other ones opt for a more critical and plural approach. The latter is open to a metanarrative deliberation on the creation of conflicting and disruptive memories in today's cultural and literary Spain.
\end{abstract}

Key words: Contemporary historical novel; División Azul; World War II; Historical memory. 
Uno de los géneros más exitosos en la literatura española contemporánea es sin duda alguna el de la novela histórica, que a partir de su desarrollo en el siglo XIX se ha explayado de manera especial en los momentos de transiciones, crisis o cambios y renovaciones políticas y culturales (García de la Rasilla 2015, 7).

Como es sabido, las reivindicaciones de los movimientos sociales de los años 90 en aras de la reapertura de un debate público acerca de la Guerra Civil y la dictadura, la fundación en el año 2000 de la Asociación para la Recuperación de la Memoria Histórica y la promulgación en 2007 de la Ley de Memoria Histórica durante el gobierno socialista de José Luis Rodríguez Zapatero tienen como correlato, en el ámbito literario, el surgimiento de lo que se denomina nueva novela histórica a comienzos del siglo XXI. En este contexto, la literatura se convierte en uno de los medios aptos para enunciar lo que es percibido como faltante (Certeau 2006, 44); eso es, un pasado que necesita ser rescatado del olvido o la censura. Además, el gran interés que sigue suscitando hoy en día el pasado bélico y dictatorial ha convertido el género literario que de la reelaboración ficticia de este periodo se ocupa en uno de los motores más efectivos de la industria cultural española de la democracia (Gómez López-Quiñones 2011, 112); que, haciendo hincapié en las predilecciones del público, ha conseguido también importantes logros comerciales y económicos.

La nueva novela histórica tiene, pues, unos cuantos rasgos peculiares ya profundizados por la crítica en las últimas dos décadas aproximadamente: ante todo, se divisa en ella un acercamiento al pasado que se modifica con respecto a la sensibilidad dominante del posmodernismo que va declinando a finales del siglo $\mathrm{XX}$, recuperándolo de manera subjetiva pero a partir de una serie de datos históricos verificables y llegando a una representación del tiempo «como una entidad dúctil sobre la que imprimir la conciencia del observador» (Navajas 1996, 28).

Por su estrecho vínculo con las reflexiones concernientes a la memoria histórica en la sociedad, la nueva novela histórica no solo apunta a recuperar un pasado olvidado o silenciado por la narración dominante (Aguado 2001, 47; Benvenuti 2012, 7; Liikanen 2012, 43-44; Moreno-Nuño 2006, 70; 2016, 103), es decir, por la propaganda o el relato impuesto por el régimen; sino que se centra preferentemente en la ficcionalización de las experiencias de las víctimas de la Guerra Civil y de la posterior represión dictatorial, de los vencidos, de esos grupos sociales subalternos cuyas voces fueron expulsadas del discurso histórico hegemónico (Juliá 2006, 17; Liikanen 2012, 43; Mate 2009, 21; Olmos 2009, 11). Es, además, una recuperación presentista y sentimental (Rodrigo 2013, 113), fundamentada en una supuesta obligación moral hacia la investigación de ese pasado olvidado y que establece con el objeto de sus indagaciones -las experiencias traumáticas de las víctimas- unas relaciones afectivas, dictadas por sentimientos como la identificación o la solidaridad más que por razones genealógicas y biológicas (Faber 2011, 102-103; 2014, 148; Hansen y Cruz Suárez 2012, 31).

Finalmente, lo realmente novedoso del enfoque literario y teórico de la nueva novela histórica reside en el surgimiento de un multiperspectivismo 
axiológico que mira a la ruptura de la representación maniquea de la Guerra Civil y del llamado patrón de las dos Españas (Hansen 2012, 89-96). Sin embargo, la propuesta teórica de Hansen, aunque fecunda, no tiene en cuenta el hecho de que esta literatura -que puede considerarse idealmente republicana (Ranzato 2006, 65), o heredera de esa cosmovisión- sigue perpetuando a menudo ese mismo tópico de la dos Españas pero invertido de signo (Moreno-Nuño 2006, 36-37), es decir, una división y representación del mundo de la Guerra Civil y la dictadura que continúa pivotando en un andamiaje dicotómico y maniqueo ${ }^{1}$. Y que además también asistimos, en el siglo XXI, al resurgimiento de posturas revanchistas de derechas que, tanto en la literatura como en el ámbito historiográfico, reaccionan a los relatos de la memoria histórica reactivando unos paradigmas interpretativos acerca de la Guerra Civil típicos del primer franquismo (Hansen y Cruz Suárez 2012, 33; Rodrigo 2013, 130, 133)2.

La mayoría de las obras que se pueden adscribir al género de la nueva novela histórica se centran pues en las experiencias de las víctimas, generando contrarrelatos que les restituyen el derecho de palabra, a la vez que apuntan al reequilibrio de las políticas del recuerdo en las que, entre otras cosas, el régimen de Franco pretendió basar su legitimidad, mediante una insistencia machacante en el culto a los caídos de su propio bando (Rodrigo 2013, 58).

Sin embargo, de este auge de interés para con el pasado reciente se quedan básicamente excluidas las vivencias de otros grupos sociales que formaron parte del régimen. Cabe mencionar que ya durante el franquismo algunos de esos grupos, tales como los veteranos de la División Azul -el contingente mayoritariamente falangista enviado a la Unión Soviética para luchar al lado del ejército de la Alemania nazi en la Segunda Guerra Mundial ${ }^{3}-$, terminaron

${ }^{1}$ Un ejemplo de representación todavía maniquea de los sucesos relacionados con el enfrentamiento bélico y el periodo dictatorial son las novelas históricas El corazón helado (2007), Inés y la alegría (2010), El lector de Julio Verne (2012) y Las tres bodas de Manolita (2014) de Almudena Grandes (Possi 2015). Otros autores que subsisten en una dicotomía neta entre el bando franquista y el republicano son por ejemplo Benjamín Prado, Alfons Cervera, Pío Moa, Juan Manuel de Prada o Alejandro M. Gallo, dejando patente cada uno de ellos en sus obras el sentimiento de afiliación ideológica y sentimental hacia uno u otro bando.

${ }^{2}$ Esta nostalgia para con «un tiempo donde el bien y el mal estaban nítidamente separados en dos mundos, [...] donde la mirada social demarcaba perfectamente las identidades, las conductas morales y la cordura» (Pereda 1997, 28), y la consiguiente construcción de relatos nuevamente maniqueos, conlleva el riesgo de unas representaciones de la guerra y la dictadura que adolecen de melancolía, victimismo y sentimentalismo exacerbados, banalizando el pasado y quitándole precisamente esa profundidad histórica que se le quería devolver (Moreno-Nuño 2006, 82; Cossalter 2009, 40).

3 La División Azul fue una unidad voluntaria formada por militares y militantes falangistas que luchó en la Unión Soviética desde julio de 1941 hasta octubre de 1943 en la Operación Barbarroja organizada por la Alemania nazi. Su génesis estriba en las tensiones internas al régimen entre la facción de los militares y la de los falangistas (Moreno Juliá $2015,32)$ y las presiones de los sectores germanófilos del mismo. Los falangistas organiza- 
siendo ignorados por el relato hegemónico dictatorial, convirtiéndose en una clase de memoria incómoda para las mismas élites franquistas, y más tarde para la España democrática también.

La memoria de la División Azul es, paradójicamente, «la memoria amarga de los "perdedores" dentro del bando de los "vencedores"» (Núñez Seixás 2005, 88), y la gesta divisionaria resultó ser, para los propios integrantes, un fracaso histórico no solamente por la derrota en la Segunda Guerra Mundial de las fuerzas del Eje, sino también por razones internas al mismo régimen. Se pueden mencionar: la imposibilidad de llevar a cabo en España una revolución auténticamente falangista (Núñez Seixás 2005, 88); el rechazo progresivo del régimen hacia esa experiencia para congraciarse con los que iban a ser los ganadores de la guerra, Gran Bretaña y los Estados Unidos, que antes lo empujó al retiro de la División en otoño de 1943 (Moreno Juliá 2015, 288, 295) y luego a presentarla «como una empresa eminentemente anticomunista y [...] oscureciendo la germanofilia de sus promotores y de muchos de los voluntarios en 1941» (Núñez Seixás 2005, 88); la acogida más bien fría con que fueron recibidos los soldados repatriados, desde el primer relevo de 1942 hasta la vuelta en 1954 de los últimos cautivos a bordo del barco Semíramis (Moreno Juliá 2005, 244-245, 336-338); y finalmente, el intento si no de silenciar, sí de marginalizar esa memoria en la posguerra, que se tradujo en una general carencia de apoyo institucional (Caballero Jurado e Ibáñez Hernández 1989, 20)4 ${ }^{4}$. Tampoco en la época de la Transición la memoria y el relato divisionarios encontraron su espacio dentro del debate público y cultural, pues sus recuerdos concernían a un grupo social vinculado con la dictadura -aunque con un esta-

ron una manifestación callejera multitudinaria el día 24 de junio de 1941 ante la sede de la Secretaría General del Movimiento en la calle de Alcalá para solicitar el envío de tropas voluntarias al frente ruso (Salas 1989, 250), y las peticiones directas de Ramón Serrano Suñer a Franco hicieron posible que el dictador accediera a la formación del contingente (Moreno Juliá 2015, 66, 72). El primer núcleo de voluntarios que salió hacia la Unión Soviética en el mes de julio de 1941 constaba de alrededor de 18.000 enrolados (Rodríguez Jiménez 2012, 105) y en los dos años de actividad pasaron por la División entre 45.500 y 47.000 hombres (Moreno Juliá 2015, 6; Rodríguez Jiménez 2012, 118; Salas 1989, 268).

${ }^{4}$ Caballero Jurado e Ibáñez Hernández inciden en que la falta de apoyo del régimen se hizo patente con respecto a la publicación de la literatura divisionaria, biografías, memorias y novelas de los veteranos que apenas encontraron cabida en editoriales como la Editorial Ejército o Ediciones del Movimiento. Al contrario, los textos divisionarios fueron publicados por editoriales directamente vinculadas con personajes falangistas, como las barcelonesas Luis de Caralt, Acervo y AHR o la madrileña Ediciones Martes, propiedad del escritor y exdivisionario Tomás Salvador (Caballero Jurado e Ibáñez Hernández 1989, 16-17). Sin embargo, Núñez Seixás afirma que los veteranos de la División Azul procedentes de las jerarquías militares obtuvieron a su vuelta a España condecoraciones y ascensos más rápidos con respecto a aquellos que no participaron en las operaciones bélicas en la Unión Soviética (Núñez Seixás 2005, 89), resaltando que si sus textos no tuvieron resonancia pública, sus carreras no fueron truncadas por su experiencia bélica, al revés. 
tuto peculiar-, y su rescate podía interpretarse como una clase de perpetuación de los mecanismos de legitimación del régimen.

Aun así, en el contexto actual de recuperación de la memoria histórica, sí empieza a resurgir un cierto -aunque tímido- interés por esa experiencia, tanto académico como literario ${ }^{5}$, ya que, después de la revisión del franquismo llevada a cabo historiográficamente en las últimas décadas, hace falta ahora «volver a revisar aquello que no ha dicho, aquello que falta por averiguar y aquellos puntos de vista que pueden desestabilizar el discurso hecho» (Gracia 2014, 194). Y la experiencia bélica en la Unión Soviética al lado del ejército alemán fue, sin duda alguna, un episodio de los que nunca nadie quiso hacer especial alarde, aparte de unos cuantos veteranos extremadamente ideologizados en su día 6 .

Pese al intento general de la nueva novela histórica de matizar y desactivar esos relatos dicotómicos propios de la posguerra que se asentaban en oposiciones simplistas tales como «España/antiEspaña, vencedores/vencidos, patriotas/ traidores o, en definitiva, buenos/malos» (Rodrigo 2013, 35), sigue dándose en parte de la narrativa del siglo XXI cierto planteamiento maniqueo en la representación de la División Azul. Por eso, existe un primer grupo de novelas publicadas en estos últimos años en las que la ficcionalización de las vivencias

${ }^{5}$ A nivel de la crítica literaria, una prueba del resurgimiento de interés por la literatura fascista es la reedición, revisión y ampliación en 2013 del texto Falange y literatura. Antología (1971) de Mainer, o de los dos volúmenes de la Literatura fascista española (19811982) de Rodríguez Puértolas en 2008. En lo que concierne a la literatura memorística, en 2013 también se reeditaron en Fórcola los Cuadernos de Rusia. Diario 1941-1942 (1978) de Dionisio Ridruejo, con un detallado estudio de Núñez Seixás y prólogo de Jordi Gracia. Finalmente, y con respecto a la novelística sobre la División Azul publicada en el siglo XXI, podemos señalar a título de ejemplo las obras El tiempo de los emperadores extraños (2006) de Ignacio del Valle -cuya adaptación cinematográfica de 2011 por Gerardo Herrero se titula Silencio en la nieve-, Añoranza de la guerra (2011) de Blanco Corredoira, Niños feroces (2011) de Lorenzo Silva, Me hallará la muerte (2012) de Juan Manuel de Prada, El peluquero de la División Azul (2014) de José Ignacio Cordero, y algunos episodios de las novelas El corazón helado (2007) de Almudena Grandes y Sonaron gritos y golpes a la puerta (2012) de Pío Moa.

${ }^{6}$ Me refiero en particular a las novelas escritas por exdivisionarios en la década de los 40 como Ida y vuelta (1946) de Antonio José Hernández Navarro, Canción de invierno en el Este. Crónicas de la División Azul (1945) de José Luis Gómez Tello, ¡Guerra! Historia de la vida de Luis Pablos (1944) de Rodrigo Royo, y parcialmente El sol y la nieve (1956) del mismo autor, en las que es patente la mitificación de la experiencia bélica, la exaltación de la ideología falangista, la presentación heroica de los personajes y el misticismo guerrero que revisten la reelaboración literaria de las hazañas de los soldados en el frente (Possi 2016a, 205-206). En estos textos, además, los divisionarios se presentan «como los últimos y frustrados fascistas verdaderos de España. Por ello, también cultivaron una imagen de sí mismos como últimos románticos, elementos incómodos que permanecían fieles a los ideales revolucionarios de juventud y menospreciados por las jerarquías del partido único franquista» (Núñez Seixás 2005, 100). 
de los divisionarios se rige en el andamiaje ideológico, más o menos velado, del autor o la autora de los textos.

Pertenecen a este conjunto de obras novelas como El corazón helado (2007) de Almudena Grandes y Sonaron gritos y golpes a la puerta (2012) de Pío $\mathrm{Moa}^{7}$, aunque su planteamiento ideológico es opuesto. Ante todo, es menester señalar que ninguna de las dos novelas está centrada en la reelaboración de la experiencia divisionaria, sino que las vivencias de Julio Carrión (El corazón helado) y Berto (Sonaron gritos y golpes a la puerta) en la Unión Soviética son simplemente una etapa más en las biografías ficticias de los dos personajes, que a grandes rasgos certifica la postura ideológica de ambas figuras según se va desarrollando la narración.

El corazón helado (2007) es una monumental novela de más de mil páginas que retrata las historias de las familias de los dos protagonistas, Álvaro y Raquel, respectivamente pertenecientes al bando vencedor y perdedor de la Guerra Civil. Central, en la narración, es el deseo de venganza de Raquel contra el padre de Álvaro, Julio Carrión, reo de haber estafado y depredado de todos sus bienes a la familia de su abuelo Ignacio, exiliada en Francia después de la derrota republicana. Julio Carrión se convierte pues, de forma un poco simplista, en el acarreador de buena parte de las desgracias del abuelo de Raquel, el personaje que a lo largo de toda la novela se convierte en un auténtico héroe, el portador de todos los valores positivos que la autora atribuye a la facción republicana en sus novelas históricas: «Ignacio Fernández Muñoz, alias el Abogado, defensor de Madrid, capitán del Ejército Popular de la República, combatiente antifascista en la segunda guerra mundial, condecorado dos veces por liberar Francia, rojo y español» (Grandes 2012, 49) ${ }^{8}$.

No sorprende pues que Julio Carrión se convierta en la figura antagónica de este intachable paladín republicano, y que el esbozo de las cualidades negativas del personaje transite también por su militancia política y su alistamiento en las filas de la División Azul, ya que al estallar la Guerra Civil, Julio era

${ }^{7}$ Las obras historiográficas de Pío Moa han suscitado en la comunidad académica agrias críticas por pertenecer a la corriente del «revisionismo historiográfico de la extrema derecha» (Hansen y Cruz Suárez 2012, 33) y por la falta en ellas de «voluntad historiográfica de comprensión del periodo; hay una estrategia políticamente programada desde la segunda legislatura de Aznar» (Gracia 2014, 191). Las posturas y los trabajos de Moa historiador fueron y siguen siendo tan impactantes que el catedrático Alberto Reig Tapia llegó a publicar un texto, elocuentemente titulado Anti-Moa (2006), para confutar los planteamientos de este autor. Pío Moa novelista, como veremos, no se aleja de la misma proposición revanchista que la propagada en su producción historiográfica.

${ }^{8}$ Según Almudena Grandes, la tradición y el legado republicanos son «la mejor tradición de la historia de este país» (Grandes 2014, 747-748). Ignacio, en El corazón helado (2007), es presentado en más ocasiones como un verdadero héroe republicano del pueblo, al haber luchado con honor y haber sido condecorado tanto en la Guerra Civil española como en la resistencia francesa durante la Segunda Guerra Mundial (Grandes 2012, 50, 347). 
solo un adolescente. Por eso, Julio Carrión es un hombre básicamente despreciable en el presente de la narración, «rico, poderoso e inculto, como suelen ser incultos los hombres ricos y poderosos» (Grandes 2012, 430), y también su pasado se reviste de un aura de negatividad. Si el hijo Álvaro siempre había sabido de la militancia del padre Julio en la División Azul, pues el hombre nunca lo había ocultado en la familia aunque no le gustase demasiado rememorar esa experiencia (ibíd., 394), es solo cuando este muere que Álvaro encuentra en su despacho la documentación relativa a su alistamiento y participación en la campaña de Rusia y algunas fotos de la época (ibíd., 379). Sin embargo, junto a eso se hallan «dos carnés a nombre de Julio Carrión González, ambos emitidos en Madrid y ambos en verano, uno en julio de 1937, otro en junio de 1941. El primero era de la Juventud Socialista Unificada. El segundo, de Falange Española Tradicionalista y de las JONS» (ibíd., 430).

El descubrimiento del malabarismo político de este personaje no hace sino reforzar esa imagen rotundamente negativa que le otorga el ser el oponente y el causante de los infortunios en el exilio del héroe de la novela, Ignacio. Al fin y al cabo, Julio Carrión no es ni siquiera un representante ideologizado del bando opuesto, sino más vulgarmente un aprovechado de la convergencia política que más le convenga en un momento dado. Julio Carrión «no era fascista $[\ldots]$ porque su posición política tenía mucho más que ver con lo que detestaba que con el anhelo de transformar la realidad en ninguna dirección. Era anticomunista, desde luego, $[\ldots]$ pero, por encima de todo, despreciaba la política y a los políticos» (ibíd., 392).

Por eso, el paso de Julio por la Unión Soviética con la División Azul es representado en la novela en el sexto capítulo de la segunda parte, donde el narrador omnisciente nos cuenta algunos de los episodios de los que es protagonista en ese escenario, pero a la vez la autora no retrata ningún acontecimiento bélico relevante. El personaje, de hecho, no estuvo involucrado ni en la expedición del lago Ilmen en enero de 1942 (Moreno Juliá 2015, 171; Rodríguez Jiménez 2012, 112) ni en la cruenta batalla de Krasny Bor en febrero de 1943 (Moreno Juliá 2015, 184-187; Rodríguez Jiménez 2012, 116), de la que se libra por haber sido herido de levedad justo pocas semanas antes (Grandes 2012, 383, 488). De esta manera, la experiencia divisionaria de Julio Carrión en El corazón helado (2007) es funcional a la caracterización de ascendencia maniquea del personaje, y pese a hacer referencia a esa memoria, los sucesos bélicos de la División Azul no se convierten en un tema secundario siquiera, imposibilitando una reflexión esmerada acerca de la controvertida participación de España en la Segunda Guerra Mundial al lado de la Alemania nazi.

En Sonaron gritos y golpes a la puerta (2012) de Pío Moa, el tratamiento de la memoria divisionaria es parecido aunque invertido de signo, pues la novela se caracteriza por la exhibición de una ideología derechista, además de ser abiertamente revanchista, al reactivar en su narración muchos de los tópicos del relato del primer franquismo acerca de la Guerra Civil, a saber: la justifi- 
cación del Alzamiento como reacción a la violencia durante los meses de gobierno frentepopulista en 1936; la insistencia en la representación del así llamado terror rojo y la demonización del oponente republicano (Rodrigo 2013, 20, 22); en suma, el enfrentamiento entre el bando nacional símbolo del Bien y del republicano del Mal ontológicos.

La novela es narrada en primera persona por Berto, desde la Guerra Civil en Barcelona cuando se convierte en un miembro de la quinta columna hasta su actuación como infiltrado en una partida de maquis en la posguerra para desarticularla desde su interior. Entre medias, la militancia del personaje y su compromiso vital con la lucha contra las fuerzas de la izquierda es ensalzada por su enrolamiento en la División Azul y su marcha a la Unión Soviética para combatir contra «la peste roja» (Moa 2012, 141).

Berto representa pues al derechista entregado a la causa, al militante ejemplar, de forma igual y especular a la mitificación del personaje Ignacio en $E l$ corazón helado (2007): es la summa de las cualidades del perfecto partidario del régimen franquista. A lo largo de la rememoración que hace de su vida, deja bien claro que su primer acercamiento a la política, con su afiliación a la quinta columna barcelonesa, responde al «deseo de contribuir a la derrota de un régimen que representaba lo contrario de lo que yo juzgaba digno de vivirse» (ibíd., 125), eso es, el republicano. Como justificación a esta elección, Berto alude a una larga serie de tropelías perpetradas por el bando contrario, llevando a cabo esa demonización del oponente que remonta a la primera propaganda franquista. Según el narrador, no solo la facción republicana es una «ciénaga de partidos dedicados a engañarse mutuamente» (ibíd., 69), sino que es responsable de crímenes aborrecibles: asesinatos y robos indiscriminados, saqueos, profanaciones de monasterios e iglesias, torturas y violaciones (ibíd., 30, 47). Para profundizar en este imaginario disfórico, Berto insiste también en las divisiones internas a la propia izquierda, relatando el enfrentamiento cruento entre comunistas y anarquistas que supone nuevamente matanzas, detenciones arbitrarias, juicios someros, fusilamientos, encierro en campos de concentración (ibíd., 106, 124), destacando en esta representación la imagen de un enemigo en lucha ante todo contra sí mismo. Los dirigentes políticos de la izquierda, además, son culpables de rapiñas de dinero, joyas y obras de arte, con que huyen al exilio en el momento de la derrota, abandonando la población a su destino y hasta llegando a utilizar como medio de transporte de su fuga vergonzosa las ambulancias (ibíd., 185-186). Además, los políticos republicanos están compinchados con los servicios secretos soviéticos que dirigen el SIM, el Servicio de Información Militar, que practica "torturas "científicas"» y se explaya en crueldades indecibles para cazar a los integrantes de la quinta columna (ibíd., 140).

Esta referencia a las injerencias de la Unión Soviética en la Guerra Civil explica la posterior decisión de Berto de alistarse en la División Azul e ir a luchar contra el «enemigo ontológico, [...] la Rusia comunista» (Rodrigo 2013, 66), en 
su propia tierra9; además de funcionar como mímesis del discurso oficial del régimen sobre la intervención de los voluntarios españoles en la Guerra Mundial, que presentaba: «aquella acción bélica como una cruzada contra la barbarie asiática, un episodio más del enfrentamiento secular de la civilización occidental con los pueblos de más allá del río Dniéster» (Moreno Juliá 2015, 72).

Por eso, lo que más llama la atención en la parte de Sonaron gritos y golpes a la puerta (2012) dedicada a la experiencia de Berto en Rusia es la descripción de los enemigos rusos y la transferencia a ellos de los mismos caracteres disfóricos empleados en la representación de los pertenecientes al bando republicano en la Guerra Civil que acabamos de comentar. Berto relata pues la crueldad esmerada de los soviéticos, que mutilan a los divisionarios de forma brutal, cortándoles los genitales y las orejas y sacándoles los ojos antes de matarlos (Moa 2012, 355), de manera parecida a las descripciones de los soldados comunistas que se encuentran en otra novela de tema divisionario, $\mathrm{Me}$ hallará la muerte (2012) de Juan Manuel de Prada ${ }^{10}$. En esta última obra se hace referencia de manera reiterada a la despiadada expoliación de los cadáveres de los voluntarios españoles por parte de los miembros del ejército soviético (Prada 2013, 121) y de los escarnios del que son objeto los muertos por parte de la población civil también, como cuando se describe a una mujer que «se encaramó sobre los cadáveres de los españoles, enarbolando el puño izquierdo y desabrochándose la guerrera con la otra mano, para enseñar a los circunstantes un seno descolgado y nada túrgido» (ibíd., 122). El sadismo de las tropas soviéticas es evidente también en el momento en que, en la misma novela, a un soldado español cautivo se le amputan dos dedos congelados sin anestesiarle siquiera (ibíd., 158); o cuando se relata, en Niños feroces (2011) de Lorenzo Silva, el episodio histórico de la masacre de los divisionarios en la llamada Posición Intermedia, cuyos cadáveres fueron hallados mutilados y clavados en el suelo con bayonetas y picos para el hielo (Silva 2012, 121-122; Moreno Juliá 2015, 169).

${ }^{9}$ La decisión y las razones de Berto reflejan de manera fidedigna los acontecimientos históricos que culminaron en el envío de los voluntarios al frente soviético, desde la aplicación de las estrategias narrativas del relato de la Cruzada como exégesis de la Guerra Civil a esta nueva Cruzada contra el comunismo (Rodrigo 2013, 66), hasta la culpabilización de la Unión Soviética como principal responsable de la guerra en España por las jerarquías falangistas (Moreno Juliá 2015, 70), que se resumió en el célebre discurso de Serrano Suñer desde el balcón de la sede de la Falange el 24 de junio de 1941: «Rusia es culpable! ¡Culpable de nuestra Guerra Civil! ¡Culpable de la muerte de José Antonio, nuestro Fundador, y de la muerte de tantos camaradas y tantos soldados caídos en aquella guerra por la agresión del comunismo ruso! [...] ;El exterminio de Rusia es exigencia de la Historia y del porvenir de Europa!» (Moreno Juliá 2015, 75).

${ }^{10}$ Ya el título de la novela es elocuente con respecto al planteamiento mayoritariamente revanchista que se da en ella, siendo una cita de un verso del Cara al sol, el himno de la Falange. 
La novela de Moa desactiva también el relato de la violencia de los divisionarios hacia la población rusa, pues si es verdad que se asiste a la violación de una joven mujer por parte de un soldado español, Saavedra (Moa 2012, 327), poco después, en un pasaje en que los divisionarios disparan y matan a un espía, se descubre que el cadáver es de esa misma mujer, que se había acercado anteriormente al grupo de españoles - de hecho, era la amante ocasional de uno de ellos- para traicionarlos y señalar su posición al ejército soviético (ibíd., 329). Además, la condena que debería recaer sobre la violación de la mujer es mitigada por otra circunstancia, pues un teniente, hablando de Saavedra, le cuenta a Berto que «los rojos mataron a dos hermanos suyos en Madrid, y a un sobrino pequeño le estrellaron la cabeza contra la pared. Nada le bastaba para vengarse» (ibíd., 2012, 346). Como ya en el relato justificativo de las violencias del bando nacional durante la Guerra Civil, aquí también los maltratos hacia la población rusa se exculpan como una reacción a las brutalidades anteriores del otro bando.

Se puede pues decir que, como en El corazón helado (2007), la participación de Berto en la campaña de la División Azul, cuya representación termina siendo más bien anecdótica y manierista, es básicamente funcional a la caracterización - esta vez positiva - del personaje, cuyo objetivo es ensalzar su valía como militante de la derecha que se entrega a la lucha anticomunista desde la Guerra Civil hasta la represión del maquis, construyendo, eslabón a eslabón, una imagen de ascendencia heroica y corte rotundamente maniqueo del narrador Berto.

También en Me hallará la muerte (2012) de Juan Manuel de Prada encontramos una mitificación parecida de los personajes derechistas, aunque en este caso la novela esté mayormente centrada en la experiencia divisionaria y no abarque como la obra de Moa un paréntesis cronológico tan amplio. En la novela de Prada, sin embargo, el heró́smo no le corresponde al protagonista del relato, Antonio, un ladronzuelo madrileño que decide alistarse en la División Azul para escapar de España después de haber matado accidentalmente a una de las víctimas de sus torpes robos (Prada 2013, 58), sino a otro personaje, el alférez Gabriel Mendoza, un camisa vieja que, físicamente, se le parece tanto que casi le da la impresión al protagonista «de contemplar su rostro reflejado en un espejo» (ibíd., 99).

Mendoza es presentado por el narrador, antes de que Antonio le conozca, como un militante impoluto, un estudiante de medicina perteneciente al SEU que interrumpe los estudios sin vacilar para ir a luchar contra el comunismo en su propio país; y además es un soldado extremadamente valiente, que ha combatido y sobrevivido a las batallas más cruentas de la División Azul en Rusia (Prada 2013, 77). Mendoza es pues un combatiente hábil y despiadado para con el enemigo, como se pone de manifiesto en varias ocasiones ${ }^{11}$; y será también el que

11 Antonio y Mendoza se conocen en la trinchera, cuando Antonio ve a un enemigo en la lejanía y no quiere dispararle para matarle sino solo para avisarle, porque en el oponente ruso «no veía a un soldado enemigo, sino a un hombre aterido que había salido en busca de 
le guiará a Antonio en su adiestramiento como soldado, enseñándole a luchar y empezando a fomentar en él ideas anticomunistas (ibíd., 113). Cuando ambos caen prisioneros después de la batalla de Krasny Bor de febrero de 1943, la figura de Mendoza es ensalzada por su actitud, ya que se convierte en el líder de los divisionarios en el campo soviético donde están presos (ibíd., 214), organiza una huelga de hambre para quejarse de las condiciones inhumanas del cautiverio pese a los estragos que esto provoca en su propia salud (ibíd., 197) y da muestra de una entereza que suscita admiración hasta en los propios carceleros (ibíd., 193, 214). Antonio, en cambio, demuestra toda su debilidad en el momento de convertirse en el amante de Nina, una mujer francesa que ya había combatido en la Guerra Civil y ahora está de traductora en el campo, y sobre todo cuando acepta espiar a Mendoza para ella (ibíd., 201). Finalmente, a la muerte de este, Antonio le suplantará por su gran parecido, para calmar y postrar a las tropas españolas, que siguen siendo las más insumisas, aprovechándose del prestigio que había adquirido Mendoza entre los divisionarios cautivos.

La semejanza física entre los dos personajes, colindante la perfección, establece en la novela un nivel de lectura guiado por el motivo del doble ${ }^{12}$ que puede simbolizar la experiencia divisionaria, con sus militantes ideologizados y aquellos que en cambio se alistaron por afán de aventura o para «poner un punto y aparte a un pasado oscuro» (Moreno Juliá 2015, 6), como en el caso del personaje Antonio. Sin embargo, la imagen de los divisionarios que se desprende de esta novela se acerca más a las nobles cualidades de Mendoza que al turbio pasado y al connivente presente de Antonio, tanto en el momento del combate -en la batalla de Krasny Bor, unos soldados moribundos, «esos valientes», llegan a hacerse explotar y perecer debajo de los tanques soviéticos para parar su avanzada (Prada 2013, 111)- como en el del cautiverio. En esa circunstancia, los españoles son los que menos se ven afectados por la propaganda comunista de sus carceleros, y los más reacios a la conversión política por la obtención de beneficios precisamente por su condición de voluntarios y no soldados de leva (ibíd., 138).

Estos retratos, y otros aspectos en los que nos detendremos más adelante, certifican en la novela de Prada un imaginario revanchista de los divisionarios, nuevamente de ascendencia maniquea; mientras que en otra novela, El tiempo de los emperadores extraños (2006) de Ignacio del Valle, la ambientación de la historia en la Unión Soviética y entre los soldados de la División Azul parece un

leña para alimentar el fuego». Sin embargo, Mendoza le aparta de la ametralladora y acaba con la vida del soldado (Prada 2013, 98-99).

${ }_{12}$ En la novela se explicita esta valía en un pasaje del texto, cuando se afirma que Antonio se había dado cuenta de que él y Mendoza eran «dos hombres de caracteres opuestos e irreconciliables, [...] El anverso y el reverso de una misma moneda, proyectando mutuamente sobre el otro un reflejo invertido, de tal suerte que si uno era cobarde el otro era intrépido, si uno era estólido el otro era resolutivo, si uno carecía de escrúpulos morales el otro los cultivaba hasta la inmolación» (Prada 2013, 198). 
simple pretexto apto para revestir el género negro del texto de tintes aún más lóbregos. El tiempo de los emperadores extraños (2006) es la segunda entrega del ciclo de novelas negras del inspector Arturo Andrade, y sus acontecimientos tienen lugar entre el final de enero y el principio de febrero de 1943 en los acuartelamientos de la División Azul ante Leningrado ${ }^{13}$, a partir del hallazgo, en el hielo de la estepa rusa y circundado por cadáveres de caballos, del cuerpo de un soldado español que ha sido asesinado, y que lleva una extraña incisión en una clavícula, donde se lee la frase «Mira que te mira Dios» (Valle 2016, 11-16). El muerto, Luis del Águila, es un falangista posiblemente alcohólico que, además, arriesga su vida en la «violeta», un juego prohibido y sin embargo extremadamente difundido entre los divisionarios y los soldados de las fuerzas del Eje, «una brutal variante de la ruleta rusa» en la que se van llenando paulatinamente las celdas del cargador de un revólver (ibíd., 88). Pese a que se insinúe que el asesinato pueda deberse a los enfrentamientos subterráneos entre los falangistas y los militares (ibíd., 102), en un primer momento el principal sospechoso es un soldado «masón, chekista y maricón» (ibíd., 202). Este hombre, quien tiene un pasado turbio en el SIM madrileño durante la Guerra Civil, le revela a Andrade que el homicidio de Luis del Águila tiene todas las señas de ser una venganza masónica, por el ritual que se divisa en la escena del descubrimiento del cuerpo (ibíd., 226). El hallazgo de otros dos cuerpos, uno con el corazón arrancado del tórax y el otro parcialmente destazado (ibíd., 248-249, 339), no hace sino ennegrecer aún más la investigación de Arturo Andrade. Finalmente, el enigma se resuelve al capturar al asesino, un poderoso masón cuyo fin es vengar la violación de su mujer en la Guerra Civil -en la que participó Luis del Águila-, mediante un oscuro ritual masónico para que su mensaje amenazador llegue al mandante de esa expedición punitiva, un hermano traidor (ibíd., 375).

En la novela de Valle, en suma, la turbia atmósfera de la División que se describe es el caldo de cultivo perfecto para una novela negra y para ambientar allí una sórdida historia de asesinatos, alcohol, masonería, juegos de azar macabros e intrigas. El frente de la Unión Soviética, con curas que bendicen las violaciones de las mujeres republicanas y soldados que son obligados a asistir a la ejecución de su propio hermano por traición y luego a cavar su tumba (ibíd., 134-137, 367), proporciona una representación desproblematizada del trasfondo histórico escogido por el autor, que es aprovechado básicamente para los fines de la investigación policial.

La novela que en cambio rompe con esta división maniquea a la hora de novelar los acontecimientos protagonizados por los voluntarios españoles que

13 Escogiendo esta cronología el autor, como ya Almudena Grandes en El corazón helado (2007), evita la representación de las dos batallas más conocidas de la División Azul, «la lucha del Segundo Regimiento del 269 al sur del lago Ladoga (enero) y la Batalla de Krasny Bor (10 de febrero)» (Moreno Juliá 2015, 184), librándose de enfrentarse con una detallada reconstrucción de los hechos históricos. 
intervinieron en la Operación Barbarroja es Niños feroces (2011) de Lorenzo Silva, que por su andamiaje metaficcional plantea unas reflexiones que son prácticamente ausentes en las otras novelas analizadas, empezando por una meditación acerca de la incomodidad de recuperar la memoria de la División Azul. Se puede decir que esta obra sigue con la serie de hitos que fundamentan el relato divisionario de los veteranos, tanto en lo que respecta a las etapas geográficas e históricas de la narración ${ }^{14}$ como en lo que se refiere a la disertación sobre ciertos argumentos: las razones del alistamiento, la ideología falangista y el desencanto, la exaltación de la guerra, el trato con la población rusa y las relaciones con los militares del ejército alemán, a los que Silva añade unas reflexiones de ascendencia pacifista y de rechazo de la guerra.

La trama de la novela se puede explicar en tres niveles: un primer marco en que Lázaro, un joven aspirante a escritor entra en contacto con un docente de escritura creativa que le insta a novelar la historia de Jorge García Vallejo, un divisionario que acaba de fallecer, y las consideraciones que le acompañan durante la reconstrucción de la historia; el relato de Jorge a ese hombre en 1989, justo después de la caída del muro de Berlín; y finalmente el tercer nivel, algunos pasajes de las vivencias de Jorge escritos por el propio Lázaro.

La novela arranca con la asistencia del narrador Lázaro al entierro de Jorge García Vallejo, al que le lleva su profesor, concurrido en su mayoría por ancianos uniformados con la camisa azul de la Falange sobre algunas de las cuales luce la Cruz de Hierro, y que termina con el canto coral del Cara al sol (Silva 2012, 29, 36). La atmósfera de la ceremonia le causa a Lázaro un hondo sentimiento de extrañeza además de una profunda impresión que ronda la conmoción y que el joven intenta rechazar, pues «en seguida me rehíce, me recordé dónde estaba, qué oía y qué había representado aquel cántico, y recobré una compostura precaria» (ibíd., 36). Lázaro se muestra en un principio muy escéptico con la sugerencia de su profesor de escribir la historia de Jorge, que después de alistarse en la División Azul siguió luchando con el ejército alemán hasta enrolarse en las SS y terminar su peripecia en la guerra en la defensa de Berlín en abril de 1945, pues el que debería ser el protagonista de su primera novela es «alguien que se incorporó a la organización que a lo largo de la Historia más cerca ha estado de encarnar el mal absoluto [...] se trata de lo peor entre lo peor» (ibíd., 51).

A partir de la elección del argumento de la historia que quiere escribir, Lázaro se adentra en la biografía de Jorge García Vallejo, su propio personaje, y se

${ }^{14}$ Las etapas que componen lo que Núñez Seixás denomina el via crucis divisionario serían: el alistamiento en España, la instrucción militar en Alemania en los campos de Grafenwhör o Hof, el viaje hacia Rusia, los combates, las penurias de la vida cotidiana y la vuelta a España; en el caso de algunos centenares de militantes, estos hechos se alargarían hasta comprender el cautiverio o su paso por la Legión Azul y sucesivo enrolamiento en las SS y la intervención en la defensa de Berlín (Núñez Seixás 2005, 97). 
detiene en las motivaciones que le llevaron antes a hacerse falangista y luego a luchar con la División Azul. Siguiendo un tópico difundido, Jorge se hace falangista por el entorno familiar derechista, pero sobre todo como reacción a un hecho de sangre que le ocurre a su familia durante la Guerra Civil, es decir, la detención arbitraria del padre por parte de unos soldados republicanos, y su posterior ejecución en Paracuellos del Jarama (Silva 2012, 61-69). Asimismo, el personaje Berto en Sonaron gritos y golpes a la puerta (2012) sufre una experiencia parecida, ya que su padre es asesinado por un grupo de milicianos que irrumpe en su casa en los primeros días de la guerra (Moa 2012, 19); y también, por ejemplo, un personaje secundario de El tiempo de los emperadores extraños (2006), Galo Rodríguez, que sobrevive de forma milagrosa a una ejecución masiva en el Escorial, permaneciendo escondido a lo largo de horas entre los cadáveres de los fusilados (Valle 2016, 314). Pese a hundir sus raíces en un tópico exitoso de la nueva novela histórica, la militancia de Jorge en Niños feroces (2011) es examinada detenidamente en unas páginas de corte metanarrativo que superan las motivaciones personales del personaje para proporcionar un análisis del periodo histórico, y de la filosofía y el programa político de la Falange, en un diálogo entre Lázaro y su profesor que además se construye a partir de unos textos historiográficos señalados.

La fascinación de Jorge por José Antonio Primo de Rivera es nuevamente causa de incomodidad para Lázaro y pone de manifiesto su reparo a la hora de recuperar la memoria falangista, por la oportunidad de resucitar ciertas ideas pero sobre todo por el sorprendente reconocimiento de que algunas palabras del fundador de la Falange «me producen el escalofrío de poder subscribirlas al cien por cien. Y lo que es lo peor: de poder hacerlo desde la más estricta contemporaneidad» (Silva 2012, 80; la cursiva es mía). A Lázaro le surge la duda acerca de la versión hegemónica posdictatorial sobre la Guerra Civil, y pese a condenar firmemente el fascismo, abre una dimensión discursiva sobre el papel de esa juventud frente a un orden político injusto (ibíd., 82). En el debate con su profesor, Lázaro llega pues a abarcar otra faceta de esa memoria incómoda, que es la más representada en las otras novelas analizadas, es decir, que finalmente los impulsos revolucionarios falangistas se convirtiesen «en una insidiosa mosca cojonera que a su modo puso su granito de arena para que se produjera la disgregación del régimen» (ibíd., 85).

La negación por parte de las élites franquistas de la experiencia divisionaria es más bien la única reflexión que encuentra cabida esporádicamente en las novelas de Moa, Prada y Valle, y es funcional a la caracterización de sus personajes y para enseñar el desencanto que los afligió. Para Berto, en Sonaron gritos y golpes a la puerta (2012), la mayoría de la gente tiene noticias falsas sobre la División Azul o incluso no tiene ninguna (Moa 2012, 271), y en El tiempo de los emperadores extraños (2006), Arturo Andrade vaticina el olvido para los soldados muertos en la Unión Soviética (Valle 2016, 172); pero es en Me hallará la muerte (2012) donde más se pone de manifiesto la evolución de la postura del régimen con respecto a la Segunda Guerra Mundial. Esto es patente en el momento de la salida de Antonio hacia el frente ruso, cuando el silencio siniestro 
de la estación de trenes recuerda al joven el contraste con el entusiasmo de la población a la marcha de la primera expedición divisionaria (Prada 2013, 74); y más aún a su vuelta a España en el Semíramis en 1954, cuando no solo se tilda a Franco de «gran ausente» de la ceremonia de acogida, sino que se presentan a esos últimos divisionarios como «reliquias de un tiempo periclitado, testimonios vivientes de ideales desaforados o quiméricos que el pragmatismo de hogaño prefería relegar a un desván de incuria» (Prada 2013, 289).

En la novela, también otro personaje de la Falange, Cifuentes, aduce como razones de este cambio de rumbo del régimen para con la experiencia divisionaria la molestia que suponía para aquellos en el poder la actitud revolucionaria falangista, y hasta llega a afirmar que el envío de tropas a la Unión Soviética fue una decisión pragmática que liberó a Franco de «aquella generación entusiasta que podría haber salvado España de la miseria y de la podredumbre» (ibíd., 296), respaldando así una opinión difusa entre los historiadores ${ }^{15}$. Pero es nuevamente en la novela de Silva donde esta reflexión se profundiza y se expone abiertamente mediante las palabras del profesor de Lázaro, quien le dice a su alumno que el cálculo político de Franco a la hora de permitir el envío de una división fundamentalmente falangista a Rusia -que en El tiempo de los emperadores extraños (2006) se define «la aplicación práctica de un frío malabarismo político» (Valle 2016, 37-38)- se basó, entre otros móviles, en la voluntad de: «librarse de varios miles de energúmenos falangistas: que en vez de enredar en casa desahogaran sus energías sobrantes en las estepas rusas, en las que además [...] se quedarían unos cuantos» (Silva 2012, 91-92).

El reconocimiento del fracaso de los ideales falangistas dentro del nuevo estado franquista, y del cálculo político de Franco en la oportunidad de enviar un contingente a la Unión Soviética para aniquilar los impulsos revolucionarios de la Falange, con el consiguiente desencanto que esto trajo consigo, no deja de ser otro tópico de las novelas testimoniales divisionarias que la literatura contemporánea vuelve a utilizar ${ }^{16}$; al igual que la exhibición de la ideología derechista de los

15 Moreno Juliá afirma que «la División Azul fue indirectamente factor de estabilización para el Régimen de Franco porque permitió el desfogue de muchos elementos críticos, hasta cierto punto peligrosos» $(2015,375)$. Ellwood también señala que el envío de la División Azul a la Unión Soviética respondió a la voluntad del régimen de encontrar una válvula de escape para el descontento de los falangistas más radicales (1984, 141-142), aunque incide más en la importancia de ese envío con respecto a las necesidades de no involucrarse de lleno en la Guerra Mundial, siendo pues el contingente militar la pieza clave de «una maniobra nacional e internacional planeada, ante todo y sobre todo, para asegurar la estabilidad y permanencia del régimen de Franco» $(1984,145)$.

16 Valgan como ejemplo dos pasajes de la novela El sol y la nieve (1956) de Rodrigo Royo, en el que un personaje falangista, Eugenio, afirma haberse enrolado en la División «por asco, $[\ldots]$ porque después de tres años de lucha fratricida, de matarnos los unos a los otros, ahora volvemos otra vez a las andadas, y vienen los enemigos de siempre y nos arrebatan la bandera, y nos echan a un lado, como si nosotros hubiésemos ido a matarnos por 
personajes y cierta exaltación de la guerra que en Niños feroces (2011) siguen perpetuándose a través del personaje Jorge y otro soldado, Laureano Grau, que a partir de la batalla de Krasny Bor se convierte en su compañero de aventuras.

En ningún momento de la narración de las andanzas juveniles de Jorge, desde su alistamiento en la División Azul hasta la fuga de Berlín y la definitiva vuelta a España en junio de 1945, el narrador intenta ocultar las razones ideológicas de su personaje. Se habla abiertamente de la militancia falangista de Jorge, de su afiliación al SEU, de su emoción a la hora de asistir al discurso de Serrano Suñer desde el balcón de la Secretaría General de Falange y del fervor que le empujan al alistamiento (ibíd., 72, 78, 90, 93). Y también de su fanatismo guerrero, de su decepción por no haber entrado todavía en combate en los primeros meses de permanencia en el campo de batalla en el río Voljov (ibíd., 122) y del rechazo a ser repatriado después de haber cumplido un año en el frente y la petición de traslado a la compañía de zapadores, donde «creyó que tendría por fin la acción que tanto había anhelado» (ibíd., 189). La exaltación belicista de Jorge se manifiesta asimismo en los recuerdos que el personaje comparte con el profesor de Lázaro en 1989, cuando le cuenta la decepción para con el régimen después del retorno a España a consecuencia de la herida que él mismo y Laureano Grau sufrieron en la batalla de Krasny Bor, y de la resolución a volver a traspasar la frontera para ir a luchar en la Wehrmacht, cuando «la tempestad, irresistible» (ibíd., 238), reclama a los dos veteranos. En la segunda parte de la representación de las vivencias bélicas de Jorge y Laureano se hace más acusado el exaltado idealismo de los dos, y se proporciona también una imagen colindante con lo heroico de sus actos, hasta el hecho de que en los momentos de servicio en «las Waffen-SS [...] Jorge, paradojas del destino, iba [...] a terminar de acreditar su valor moral, es decir, su capacidad de sacrificarse por sus convicciones» (ibíd., 293). Sin embargo, la decisión del personaje de entrar en las SS es presentada, más que determinada por razones ideológicas como en cambio el enrolamiento en la División Azul, por una obsesión creciente por estar en la primera línea de combate y una enajenación que imposibilita la vida de un soldado en tiempos de paz (ibíd., 289, 237), y poco tiene que ver con las opiniones de Mendoza de $M e$ hallará la muerte (2012), según el cual: «la guerra [...] es el deporte más hermoso. [...] porque en ella la vida se desnuda. Todo en ella es abierto y sincero, sin intrigas, sin hipocresías. Es otro mundo que lava los pecados cometidos en el mundo social, tan ruin, tan sucio y blandengue» (Prada 2013, 101) ${ }^{17}$.

ellos y para ellos, para sacarles las castañas del fuego, para defender su roña y su mezquindad y su atonía social y política» (Royo 1956, 37). Además de estar convencido de que la única razón del envío a Rusia de su contingente es el intento por parte de Franco de comprar la neutralidad española en la Segunda Guerra Mundial, aparentando por su medio una colaboración con Hitler por otro lado bastante escasa (Royo 1956, 77-78).

${ }^{17}$ Este pasaje de la novela de Prada reproduce, casi literalmente, las opiniones y palabras del narrador de ;Guerra! Historia de la vida de Luis Pablos (1944) de Rodrigo Royo, quien también afirma que «La guerra es el deporte más hermoso. Todos los mús- 
De hecho, la novela de Silva se aleja de posibles acusaciones de revanchismo, pues a pesar de enseñar abiertamente la ideología de su personaje, en varios pasajes el narrador condena a los protagonistas de esos acontecimientos históricos, hablando tanto de Stalin como de Hitler como de «dos seres fríos, tramposos e implacables» (Silva 2012, 88), y de los soldados de las SS como de «aquellos voluntarios fanatizados, víctimas de tácticas suicidas y de su propia ceguera ideológica» (ibíd., 297), sin dejar ninguna duda acerca de su reprobación hacia el régimen nacionalsocialista y su proceder en la guerra, extendiendo pues la misma a los soldados españoles también.

Además, se comenta que el ideal anticomunista de Jorge, en las últimas fases de su trayectoria bélica, empieza a mermar, tanto por la decepción causada por el trato continuado con los alemanes, que siempre Jorge había admirado por su disciplina (ibíd., 163), como por el desmadre general de la guerra y las contradicciones que esta resalta, que desembocan en un cansancio creciente a la lucha (ibíd., 317, 309). Pero el sentido del honor de Jorge y Laureano, y su sentimiento de vergüenza hacia lo que considerarían echarse atrás, les impide a los dos parar esa aventura que cada vez parece más descabellada (ibíd., 336).

A pesar de la glorificación de la experiencia bélica que le corresponde al personaje Jorge, Niños feroces (2011) es un texto profundamente antibelicista en el que se enseñan sobre todo los horrores de la guerra, y de manera particular en la representación antagónica que se hace de los soldados alemanes frente a los divisionarios. Si bien es verdad que este ya fue otro tópico de la narrativa escrita por los veteranos divisionarios, al igual que lo sigue siendo de los autores contemporáneos ${ }^{18}$, en la novela de Silva se convierte en un instrumento apto para ensanchar la reflexión sobre la guerra e integrar en ella acon-

culos se desarrollan por igual, y, sobre todo, la vida tiene un sentido noble, sin bajezas, sin dobleces. Todo es abierto y sincero, puro, sin intrigas, sin hipocresía. Es otro mundo que lava los pecados cometidos en el mundo social, pobre, ruin y blandengue» (Royo 1944, 148-149).

${ }^{18}$ En Me hallará la muerte (2012), por ejemplo, el capitán que hace jurar a Antonio su entrega incondicional a la lucha en el momento de su llegada al campamento de instrucción alemán le conmina distinguirse de los soldados de la Wehrmacht con respecto al trato hacia la población rusa, alegando que «esos nazis cabrones le hacen perrerías a la gente, soldado. Son unos putos chacales sedientos de sangre» (Prada 2013, 91). También en El tiempo de los emperadores extraños (2006) hay varios episodios que dan cuenta de la brutalidad de los alemanes frente a la humanidad de los divisionarios, el más emblemático de los cuales es una matanza llevada a cabo por los soldados de los Einsatzgruppen en un monasterio en Molewo, donde los internos de un manicomio se han quedado solos y desamparados por la huida de sus cuidadores (Valle 2016, 342-344). Mientras los españoles tienen un trato cordial con aquellos hombres enfermos, y hasta sienten piedad por ellos, las tropas de los Einsatzgruppen ejecutan fríamente la masacre de todos los enfermos, cuando después de haberlos reunidos en el claustro del edificio abren fuego sobre ellos frente a los españoles y a un atónito Arturo Andrade, que asiste a los acontecimientos recordando, horrorizado, «el tenebroso fetiche de la higiene social nazi» (Valle 2016, 343). 
tecimientos que pertenecen a nuestra más estricta contemporaneidad, tales como las guerras de Irak y Afganistán.

Para minimizar el hecho de que Lázaro teme no poder reproducir de manera fehaciente en su novela los acontecimientos bélicos en que interviene su personaje Jorge, su profesor le organiza dos entrevistas con militares españoles que participaron en las guerras emprendidas por los Estados Unidos después del 11S. Así, Lázaro puede tener testimonios directos de unas acciones militares, además de dialogar con los soldados acerca de las cuestiones que más le preocupan. Lo más interesante desde el punto de vista narrativo es que estas entrevistas sugieren al lector, de forma sutil, un paralelismo entre los alemanes y los estadounidenses, por un lado; y, por otro lado, entre los españoles divisionarios y los españoles contemporáneos. De ahí que el profesor de Lázaro, comentándole la participación española en el conflicto iraquí, afirme que se parece a la de los voluntarios españoles en la Unión Soviética, pues ese contingente, «como la División Azul, sirve para cubrir un expediente sin apostar más de la cuenta. El gobierno que los ha enviado, como hizo Franco, busca nadar y guardar la ropa. Se trata de estar allí, sin dar la impresión de que se está más de lo conveniente» (Silva 2012, 134). El paralelismo que se sugiere es pues el que se establece entre los alemanes en la Segunda Guerra Mundial y los estadounidenses en la guerra de Irak, al ser estos dos ejércitos aquellos que -aunque con motivaciones y objetivos distintos- empiezan con una guerra en un país extranjero e implican a los españoles, los de la década de los 40 del siglo XX y los del siglo XXI.

La equivalencia entre alemanes y estadounidenses se refuerza durante las charlas con los militares españoles, pues en varias ocasiones estos ponen de manifiesto tanto «las barbaridades que hacían los americanos» contra la población civil iraquí como el hecho que «nosotros éramos profesionales y queríamos demostrarlo» (Silva 2012, 147-148), además de resaltar siempre cierto respeto y consideración hacia unas gentes invadidas por ejércitos extranjeros (ibíd. 150). Asimismo, muchos de los recuerdos de Jorge apuntan precisamente a marcar una distancia entre la crueldad con que los alemanes trataban a los rusos y el trato cordial con la población que en cambio instauran los españoles (ibíd., 163). Finalmente, también resulta parecido el sentimiento de decepción para con las expectativas de la guerra, tanto en Jorge como en los soldados españoles que lucharon en Irak, pues en ambos casos la idea de ir a ayudar a unas poblaciones sometidas a un yugo dictatorial percibido como erróneo, cuando no maligno, termina en la impotencia, en la sensación común de haber hecho un esfuerzo inútil que no ha cambiado nada y muchísimo menos ha tenido las repercusiones positivas esperadas en la vida de los pueblos ruso e iraquí (ibíd., 147-148, 374).

A través de la insurgencia del paralelismo entre la Segunda Guerra Mundial y la guerra de Irak, Silva condena el afán belicista presente en ambos conflictos, alejándose de una representación de la memoria que Todorov ya clasificara de literal, eso es, que recupera un pasado que permanece intransitivo y no 
conduce más allá de sí mismo (Todorov 2013,33), siendo este concepto de lo más evidente en las novelas de Almudena Grandes, Pío Moa, Juan Manuel de Prada e Ignacio del Valle. En estas obras, los acontecimientos históricos concernientes a la División Azul permanecen en una dimensión narrativa y temporal que nada tiene que ver con nuestro presente y sus sucesos e inquietudes, y que al revés se ve supeditado a la reconstrucción ficticia del pasado. En la novela de Silva, por el contrario, se hace referencia a una memoria ejemplar; esto es, siguiendo nuevamente la terminología de Todorov, una memoria que no se queda estancada en una imagen estática y aislada del pasado, sino que reutiliza la singularidad de los acontecimientos «como una manifestación entre otras de una categoría más general, $[\ldots]$ como de un modelo para comprender situaciones nuevas, con agentes diferentes» (ibíd., 33) pero a la vez parecidas, que es precisamente la clave de lectura proporcionada en Niños feroces (2011) para desentrañar lo relativo a la Segunda Guerra Mundial y la guerra de Irak.

Lo mismo se puede decir acerca del interés de Lázaro, en las mencionadas entrevistas, por la conducta de los soldados españoles en la guerra, sus reacciones en combate y las maneras de sobrellevar la conciencia de ser el causante de las muertes de otras personas, que le sirve al joven narrador para intentar comprender mejor a su personaje. Como Lázaro ya no puede confrontarse con Jorge, que acaba de fallecer, busca explicaciones con aquellos que intervinieron en un teatro de guerra, pues necesita aclarar algunos puntos del relato de Jorge que le transmite su profesor, como cuando le habla del entusiasmo de los soldados a la hora del combate, y de «esa sensación de poder [...] sobre las vidas que se te pongan a tiro» (Silva 2012, 282), que ya suscitan cierta repulsión en el joven que escucha al testigo en 1989 (ibíd., 200). Por eso, Lázaro se atreve a preguntar a sus interlocutores acerca de sus sentimientos sobre las muertes causadas en el combate; las contestaciones que obtiene no reflejan ni sentido de la culpabilidad ni tampoco orgullo, pues los militares entrevistados solo sienten el impulso de la supervivencia (ibíd., 143), siendo así de tajante la conclusión de uno de los militares: «en la vida, y cuando llega la hora de la lucha se ve claro, no hay cosas buenas y malas, sino mejores y peores» (ibíd., 185), desmintiendo nuevamente la posibilidad simplista de reducirlo todo a un enfrentamiento maniqueo entre el bien y el mal, lo que termina siendo el fil rouge que le da unidad y sentido a la novela entera.

Desmontadas las primeras opiniones de Lázaro acerca de la historia que su profesor le propone novelar, el narrador acude también a la autobiografía de Günter Grass, Pelando la cebolla (2006), cuya publicación reveló al mundo la militancia juvenil de Grass en las Waffen-SS, tal y como el personaje Jorge. Lo que le interesa profundizar a Lázaro con la lectura de ese texto es nuevamente la descripción de un protagonista de los acontecimientos del proceso de alistamiento voluntario «en la gran empresa criminal del nazismo» (Silva 2012, 322). Las memorias del premio Nobel alemán le guían pues a Lázaro en el ahondamiento del tema que termina siendo el núcleo central de la novela, es decir, el de 
la juventud empujada al campo de batalla, y cuya energía, en lugar de motor de progreso y construcción de un futuro, es transformada en potencial de destrucción. Esa juventud que encarnaba el Jorge García Vallejo que se alistó voluntario para ir a luchar a Rusia en el verano de 1941. [...] Y aquel lampiño y vehemente Günter Grass que, enardecido por las imágenes bélicas de los noticieros de la UFA, se incorporó en el otoño de 1944 a las filas de la división acorazada SS-Frundsberg. [...] Y los jóvenes iraquíes y españoles que en abril de 2004 se afrontaron en Nayaf. [...] Y tantos otros como ellos, ayer y hoy, y bajo tantas banderas (ibíd., 379-380).

La meditación postrera de Niños feroces (2011), al comparar las experiencias bélicas tanto de Günter Grass como del personaje ficticio Jorge, y de aquellos jóvenes que combatieron en Irak, confirma tanto el valor del mensaje antibelicista de la novela como su reelaboración ejemplar de la memoria, lo que convierte el texto de Silva en un unicum entre las obras analizadas. Es más, el acercamiento crítico a las vivencias de un veterano de la División Azul ejemplifica de forma magistral la insurgencia del multiperspectivismo en la novela histórica contemporánea, al desmontar los prejuicios y tópicos maniqueos que suscitaban el rechazo de Lázaro hacia su personaje al comienzo de la narración, y que le llevan a abrazar la postura ideológica de su profesor. Según este último, en la representación narrativa no se trata de juzgar, justificar o condenar a ningún protagonista, sino de intentar comprender las razones que le movieron (ibíd., 52), especialmente si sus elecciones resultan ahora chocantes desde el punto de vista de aquellos que ya sabemos la posterior evolución de los eventos.

Sin embargo, la profundidad de análisis e innovadora propuesta exegética que se despliega a lo largo de toda la novela es desmentida en parte en el final, al relatarle el profesor de Lázaro a su joven discípulo su último encuentro con Jorge, pocos meses antes de su muerte. Pese a que en varios episodios de la novela ya se había dado cuenta de las dudas ideológicas de Jorge y de su paulatino alejamiento del falangismo, de su anticomunismo fanático y de una postura sostenedora de formas de gobierno antidemocráticas (Silva 2012, 300, $311,317)^{19}$, y también se había relatado su prevención en la madurez hacia los actos conmemorativos de la empresa divisionaria, nunca se había hecho referencia a un posible arrepentimiento de Jorge acerca de su intervención en la Segunda Guerra Mundial, al revés (ibíd., 372). Hasta, precisamente, el último diálogo con el profesor de Lázaro, al que Jorge confiesa que «me arrepiento. Que he comprendido que me equivoqué, que no conseguí nada y que estuve donde no debía estar. Ni yo, ni nadie. Me he empeñado toda la vida en defender aquello, pero los años me han echado abajo en el intento» (ibíd., 374). Con la ruptura ideológica del personaje con su militancia en la División Azul y posteriormente en las SS la novela pierde, por un lado, esa originalidad de novelar la vida de un personaje, Jorge, que los prejuicios coetáneos juzgarían

19 Esto es evidente en las opiniones de Jorge acerca de los golpistas del 23-F, a los que tilda de «pandilla ridícula» (Silva 2012, 197), además de negarles su adhesión. 
como negativo; y, por otro lado, el hecho de que se arrepienta pocos meses antes de morir, anula la que podría haber sido una innovadora poética de autor: el objetivo de un novelista no es gustar a su lector, sino «perturbarlo. Sacudirlo. Zarandearle las ideas asumidas, meterlo en contradicciones» (ibíd., 52). Contradicciones que, sin embargo, se desmoronan en el final justo por el arrepentimiento último de Jorge, que lleva al personaje de vuelta a una postura políticamente correcta y le salva del juicio moral al que podría someterlo el lector o, al revés, parece intentar evitar que este personaje tan logrado pueda fascinar incluso en lo que respecta a su militancia política, renegándola en los momentos colindantes con la muerte. Por eso, aunque Lázaro insista en el último capítulo de la novela que no le compete juzgar, pues cada obra literaria es básicamente «una tentativa de asomarse al misterio, que siempre se queda por decir» (ibíd., 379), la conclusión de la trayectoria vital de Jorge García Vallejo es una parcial refutación de las reflexiones planteadas a lo largo de la novela, como si la superación del maniqueísmo y la asunción de posturas plurales, críticas y activas con respecto a lo propuesto terminase siendo una opción filosófica e interpretativa inviable, máxime si concerniente a un pasado turbio como el relacionado con el nazismo.

Lo que en cambio no se ve afectado por la abjura final de Jorge es, como he dicho, el que se identifica como el mensaje central de la novela, a saber: su postura antibelicista y su valor de estímulo a la reflexión sobre los protagonistas de la Historia, «los hombres ambiciosos y los niños feroces» (Silva 2012, 384), aquellos que planifican las guerras desde sus despachos y aquellos que se juegan la vida en el campo de batalla para defender ideologías en las que al fin y al cabo no terminan creyendo. Porque finalmente, como afirma el propio autor en el aparato paratextual que cierra su obra, la historia de Jorge «no es una historia ejemplar, pero sí aleccionadora» (ibíd., 395), ya que sugiere una interpretación de los sucesos que no se queda atrapada en un pasado estático sino que se pone fecundamente en diálogo y comunicación con la estricta contemporaneidad.

En conclusión, esa memoria incómoda de la División Azul explicada al principio del artículo promueve en la novela histórica contemporánea dos planteamientos narrativos distintos. Por un lado, la utilización de los acontecimientos históricos sugiere una relectura contemporánea del pasado que se limita a una presentación de corte maniqueo, sentimental y presentista, apta para cimentar un andamiaje ideológico e identitario preconcebido, en el que la ficcionalización de la Historia no estimula la reflexión sino que cristaliza posturas preexistentes. Novelas como El corazón helado (2007), Sonaron gritos y golpes a la puerta (2012), Me hallará la muerte (2012), El tiempo de los emperadores extraños (2006) son un preclaro ejemplo. En estas obras, los autores no consiguen alejarse de una postura dicotómica en la representación de los acontecimientos históricos relativos a la División Azul, pese a los planteamientos teóricos de la nueva novela histórica concernientes al multiperspectivismo. El dogmatismo ideológico 
divisable en la novelización del relato divisionario sigue dependiendo en estos casos de una representación del pasado abiertamente subjetiva, que no logra desvincularse del maniqueísmo que había fundamentado la narrativa del siglo XX acerca de la Guerra Civil y la dictadura franquista. Las novelas mencionadas son pues el resultado de una postura doctrinaria que todavía rechaza

los matices y las complejidades de la realidad empírica para seguir sentando sus representaciones en una división categórica entre buenos y malos, lo que permite una interpretación más simple, y por eso quizás más consolatoria, de unos acontecimientos históricos que, más que heroicos, fueron trágicos, infaustos y penosos (Possi 2016b, 172).

El maniqueísmo que afecta a las novelas de Moa, Valle, Grandes y Prada refleja en suma las dificultades que aún perviven hoy en día para con la superación del pasado bélico y dictatorial de la España del siglo XX, algo que impide -también a nivel narrativo- un cambio en la representación de la memoria histórica y una reconciliación postrera con esos acontecimientos históricos.

Por otro lado, en la novela Niños feroces (2011) de Lorenzo Silva encontramos un segundo planteamiento, opuesto quizá al precedente, que propone que lo histórico sea objeto de una revisión que trasciende los lindes y las contingencias particulares de los eventos para crear conexiones entre acontecimientos distantes en el tiempo y a la vez ampliar el alcance de unas reflexiones sobre temáticas universales -como la guerra, la violencia, el poder de las ideologías a raíz de enfrentamientos y brutales matanzas- que puedan ser aprovechadas como instrumentos interpretativos también en el presente.

La obra de Silva, además, saca al lector de su zona de confort interpretativa y lo estimula a abandonar los prejuicios para dotar al pasado de múltiples lecturas que eludan las reducciones simplistas. Sin embargo, como vimos, el intento del autor de distanciarse de una representación dicotómica del pasado divisionario de su personaje, y de su personaje mismo a través de su inalterada ideología política falangista, queda frustrado en el final de la novela. El rechazo por parte del protagonista Jorge de su enrolamiento en la División Azul antes y en las Waffen-SS después, pocos meses antes de la muerte, llega a invalidar ese planteamiento novedoso acerca de la representación de los hechos históricos tratados. La que se presenta como una redención del personaje, en suma, aunque tiene lugar en una novela que apunta a la ruptura del patrón maniqueo comentado, certifica la imposibilidad que subsiste en la actualidad de presentar unas interpretaciones plurales del pasado, desligadas de las oposiciones ideológicas de ese mismo tiempo pretérito. Aun siendo Niños feroces (2011) una novela que apuesta por la superación de las divisiones dogmáticas del siglo XX, no consigue mantener coherentemente su planteamiento hasta el final, dejando claro que el perseguimiento de una visión más matizada y apegada a la realidad del pasado continúa siendo un objetivo a perseguir dentro del ámbito de la nueva novela histórica. 


\section{BIBLIOGRAFÍA CITADA}

Aguado, Txetxu. 2011. «Modelos emocionales de memoria: el pasado y la Transición». En Contornos de la narrativa española actual (2000-2010). Un diálogo entre creadores y críticos, ed. Palmar Álvarez-Blanco y Toni Dorca, 45-53. Madrid: Iberoamericana.

Benvenuti, Giuliana. 2012. Il romanzo neostorico italiano. Storia, memoria, narrazione. Roma: Carocci editore.

Caballero Jurado, Carlos y Rafael Ibáñez Hernández. 1989. Escritores en las trincheras. La División Azul en sus libros, publicaciones periódicas y filmografia (1941-1988). Madrid: Ediciones Barbarroja.

Certeau, Michel de. 2006. La escritura de la historia. México D. F.: Universidad Iberoamericana.

Cossalter, Fabrizio. 2009. «Las raíces del desencanto: notas sobre la memoria literaria de la Transición». En (En)claves de la Transición. Una visión de los Novísimos. Prosa, poesía, ensayo, ed. Enric Bou y Elide Pittarello, 39-56. Madrid: Iberoamericana.

Ellwood, Sheelagh. 1984. Prietas las filas. Historia de Falange Española, 1933-1983. Barcelona: Editorial Crítica.

Faber, Sebastiaan. 2011. «La literatura como acto afiliativo: la nueva novela de la Guerra Civil (2000-2007)». En Contornos de la narrativa española actual (2000-2010). Un diálogo entre creadores y críticos, ed. Palmar Álvarez-Blanco y Toni Dorca, 101-110. Madrid: Iberoamericana

Faber, Sebastiaan. 2014. «Actos afiliativos y postmemoria: asuntos pendientes». Pasavento. Revista de estudios hispánicos II, 1: 137-155.

García de la Rasilla, Carmen. 2015. «Introducción». En La novela histórica española contemporánea: novedades y transformaciones (Del 98 al nuevo milenio), ed. Carmen García de la Rasilla, 7-12. Valladolid: Editorial Verdelís.

Gómez López-Quiñones, Antonio. 2011. «La misma guerra para un nuevo siglo: textos y contextos de la novela sobra la Guerra Civil». En Contornos de la narrativa española actual (2000-2010). Un diálogo entre creadores y críticos, ed. Palmar Álvarez-Blanco y Toni Dorca, 111-119. Madrid: Iberoamericana.

Gracia, Jordi. 2014. «El compromiso revisionista o cómo volver a contar (Réplica a Sebastiaan Faber)». En Ensayo y sociedad. Diálogos de un género en movimiento, ed. Diana Castilleja, Eugenia Houvenaghel y Dagmar Vandebosch, 189-201. Ginebra: Librairie Droz.

Grandes, Almudena. 2012. El corazón helado. Barcelona: Tusquets Editores.

Grandes, Almudena. 2014. Las tres bodas de Manolita. Barcelona: Tusquets Editores.

Hansen, Hans Lauge. 2012. «Formas de la novela histórica actual». En La memoria novelada. Hibridación de géneros en la novela española sobre la guerra civil y el franquismo (20002010), ed. Hans Lauge Hansen y Juan Carlos Cruz Suárez, 83-103. Berna: Peter Lang SA

Hansen, Hans Laugen y Juan Carlos Cruz Suárez. 2012. «Literatura y memoria cultural en España (2000-2010)». En La memoria novelada. Hibridación de géneros en la novela española sobre la guerra civil y el franquismo (2000-2010), ed. Hans Lauge Hansen y Juan Carlos Cruz Suárez, 21-41. Berna: Peter Lang SA.

Juliá, Mercedes. 2006. Las ruinas del pasado. Aproximaciones a la novela histórica posmoderna. Madrid: Ediciones de la Torre.

Liikanen, Elina. 2012. «Pasados imaginados. Políticas de la forma literaria en la novela española sobre la guerra civil y el franquismo». En La memoria novelada. Hibridación 
de géneros en la novela española sobre la guerra civil y el franquismo (2000-2010), ed. Hans Lauge Hansen y Juan Carlos Cruz Suárez, 43-53. Berna: Peter Lang SA.

Mate, Reyes. 2009. «Historia y memoria. Dos lecturas del pasado». En La cultura de la memoria. La memoria histórica en España y Alemania, ed, Ignacio Olmos y Nikki Keilholz-Rühle, 19-28. Madrid: Iberoamericana.

Moa, Pío. 2012. Sonaron gritos y golpes a la puerta. Madrid: La Esfera de los Libros.

Moreno-Nuño, Carmen. 2006. Las huellas de la Guerra Civil. Mito y trauma en la narrativa de la España democrática. Madrid: Ediciones Libertarias.

Moreno-Nuño, Carmen. 2016. «La novela de la Guerra Civil (2000-2015) y el gusto por la réplica en Tu rostro mañana de Javier Marías». La nueva literatura hispánica 20: 99-118.

Moreno Juliá, Xavier. 2015. La División Azul. Sangre española en Rusia, 1941-1945. Barcelona: Crítica.

Navajas, Gonzalo. 1996. Más allá de la posmodernidad. Estética de la nueva novela y cine españoles. Barcelona: EUB.

Núñez Seixas, Xosé Manoel. 2005. «Los vencedores vencidos. La peculiar memoria de la División Azul, 1945-2005». Pasado y Memoria. Revista de Historia Contemporánea 4: 83-113.

Olmos, Ignacio. 2009. «Introducción». En La cultura de la memoria. La memoria histórica en España y Alemania, ed. Ignacio Olmos y Nikki Keilholz-Rühle, 7-11. Madrid: Iberoamericana.

Pereda, Rosa. 1997. Teatros del corazón. Madrid: Espasa-Calpe.

Possi, Valeria. 2015. «Nuevos maniqueísmos: los intelectuales en las novelas históricas de Almudena Grandes». En Progreso y cultura hispánica, ed. Ricardo de la Fuente Ballesteros, Jesús Pérez Magallón y José Manuel Goñi, 145-161. Valladolid: Universitas Castellae.

Possi, Valeria. 2016a. «La narrativa testimoniale nella letteratura spagnola e italiana sulla campagna di Russia». Artifara 16: 203-216. https://doi.org/10.13135/1594-378X/1562

Possi, Valeria. 2016b. «Trauma y silencio: el golpe de Casado». En El trauma en la literatura hispánica, ed. Ricardo de la Fuente Ballesteros, Jesús Pérez Magallón y José Manuel Goñi Pérez, 159-176. Valladolid: Universitas Castellae.

Prada, Juan Manuel de. 2013. Me hallará la muerte. Barcelona: Ediciones Destino.

Ranzato, Gabriele. 2006. Il passato di bronzo. L'eredità della guerra civile nella Spagna democratica. Bari: Laterza.

Rodrigo, Javier. 2013. Cruzada, paz, memoria. La Guerra Civil en sus relatos. Granada: Editorial Comares.

Rodríguez Jiménez, José Luis. 2012. «La contribución de la División Española de Voluntarios a la invasión de la URSS». Cuadernos de Historia Contemporánea 34: 91-118. https://doi.org/10.5209/rev_CHCO.2012.v34.40065

Royo, Rodrigo. 1944. ¡Guerra! Historia de la vida de Luis Pablos. Madrid: Gráficas Ultra.

Royo, Rodrigo. 1956. El sol y la nieve. Madrid: Gráficas Cíes.

Salas, Ramón. 1989. «La División Azul». Espacio, Tiempo y Forma. Serie V, Historia Contemporánea 2: 241-269.

Silva, Lorenzo. 2012. Niños feroces. Barcelona: Ediciones Destino.

Todorov, Tzvetan. 2013. Los abusos de la memoria. Barcelona: Paidós.

Valle, Ignacio del. 2016. El tiempo de los emperadores extraños. Madrid: Alfaguara.

Fecha de recepción: 07 de junio de 2017.

Fecha de aceptación: 05 de septiembre de 2017. 